\title{
Los nuevos contenidos oficiales de educación sexual en México: la laicidad en la mira
}

\section{The new official contents of sex education in Mexico: Iaicism in the crosshairs}

DOI: https://doi.org/10.32870/dse.v0i21.660

Armando Javier Díaz Camarena*

\section{Para comenzar}

A pesar de que la educación laica en México es un principio constitucional desde 1917, los contenidos oficiales no están libres de ser permeados por discursos con perspectiva católicocristiana. Esto se debe a que laicidad, entendida como la autonomía del Estado y de las políticas públicas respecto a la religión, no es un resultado directo de la separación legal; en realidad, se construye con el cambio cultural, las luchas sociales y la redefinición de mecanismos de regulación del orden social que resultan del avance de la ciencia, la respuesta a emergencias económicas, poblacionales y sanitarias, así como de la incorporación de valores democráticos en las leyes. En este trabajo reflexionaré sobre la manera en que se definen y construyen los contenidos sobre educación sexual en los libros oficiales, con un breve recuento histórico y una descripción de los debates desde 2012, pues son un indicador de los avances y retrocesos en la construcción de la laicidad (Blancarte, 2012), así como del cambiante equilibrio de poder entre el Estado, las organizaciones religiosas y actores a favor de los derechos sexuales. Para mi reflexión, me apoyo de la propuesta de Foucault (1986) acerca de estudiar la experiencia social de la sexualidad mediante la revisión de textos normativos y a partir de analizar la relación entre saber, poder y sujeto; abordaré los discursos sobre educación sexual en tres aspectos: $a$ ) los saberes y juegos de verdad que definen los contenidos, $b$ ) las relaciones de poder que hacen posibles esos discursos, y c) los tipos de subjetividad que pretenden producir. En coherencia con lo que señala dicho autor, parto de la premisa de que no se trata de ver estos discursos como simple proyección del poder, ni de hacer una división entre lo incluido y lo excluido, sino de abordar los

\footnotetext{
* Doctor en Ciencias Sociales con especialidad en Sociología. Profesor del Instituto Tecnológico y de Estudios Superiores de Monterrey, Escuela de Humanidades y Educación. Investigador sobre educación sexual y estado laico. Centro de la Diversidad y los Derechos Sexuales, A.C. México. capitanxli@hotmail.com
} 
contenidos oficiales como acontecimientos políticos que emergen en cada época y mantienen relación con otros acontecimientos discursivos del ámbito económico, político y cultural que los hacen posibles (Foucault, 1994: 63). Retomaré elementos teóricos sobre laicidad y secularización (Blancarte, 2008), pues analizar los contenidos oficiales de cada momento histórico nos permite dar cuenta de los avances y retrocesos de la laicidad dentro de condiciones políticas, materiales y culturales que los hacen posibles; podemos identificar los límites de "lo tratable y lo inevitable", pues resultan de disputas y consensos en contextos marcados por el avance de la ciencia, el cambio de la ley, el discontinuo proceso de secularización, y emergencias demográficas y sanitarias que la biopolítica no puede eludir.

\section{El papel social de la educación sexual}

Toda sociedad establece algún sistema educativo con el que forma a los sujetos, que responde a las exigencias de la vida en común, y que en cada momento de la historia está determinado por el desarrollo de las ciencias, la economía, la política y la religión (Durkheim, 2012). Bajo este principio, la educación sobre sexualidad desempeña un papel central en la formación de los sujetos para la vida social; los contenidos sobre este tema son parte del mecanismo de subjetivación, que constituye el proceso en el que los individuos toman sus posiciones en la sociedad, las cuales se encuentran definidas mediante distintos discursos (Butler, 2014: 21). Lo que entendemos como sexualidad desempeña un papel central en la organización de la sociedad porque es un área de vinculación entre sujetos, un ámbito de normatividades, luchas, definiciones y autodefiniciones (Weeks, 1998); este campo de educación ha adquirido una relevancia central para el Estado porque la sexualidad es un área en la que convergen cuerpo y población, y su regulación resulta estratégica para ejercer un biopoder, es decir, un control sobre la vida (Foucault, 2007); pero también es un área de reflexividad social (Giddens, 1998) porque es un elemento clave para la convivencia pacífica y la construcción de una sociedad igualitaria que proteja las libertades.

Los contenidos oficiales sobre educación sexual se sostienen en saberes y constituyen un mecanismo estratégico de distribución de discursos que sostienen cierto orden sexual como"legítimo"; en ellos se muestra el proyecto de sujeto que la sociedad pretende producir, por ello es que tienen un carácter performativo, es decir, que pretenden producir "los efectos que nombran" (Butler, 2010: 18). En México, cada nueva versión de contenidos oficiales ha sido objeto de disputas ideológicas e impugnaciones entre actores que buscan mantener el orden sexual judeocristiano, y actores que impulsan la inclusión de nuevos sujetos y nuevos derechos sexuales; por ello es que resultan de cierto consenso entre esas disputas, las prioridades del Estado, el avance de la ciencia y el reconocimiento de los derechos humanos, de manera que reflejan el estatus de la sociedad de cada época. El estudio de los contenidos oficiales de educación sexual da cuenta del proyecto de sujeto que la sociedad ha pretendido construir en cada momento histórico, pues sus

Diólo@os sobre Educación año 11 | número 21 | julio-diciembre 2020| ISSN 2007-2171 
textos e imágenes marcan los límites de cierto orden social de la sexualidad considerado "legítimo", materializan lo que es factible e "inevitable" incluir en la formación de los sujetos.

Parto de la premisa de que son discursos regulatorios que pretenden mantener un orden sexual "legítimo", pero que contribuyen a liberar a los sujetos, pues han implicado reconocer sus particularidades y el ejercicio del uso de sus cuerpos. Estos contenidos, como discursos, constituyen herramientas de las relaciones de poder, las cuales "no pueden disociarse, ni establecerse, ni funcionar sin una producción, una acumulación, una circulación, un funcionamiento del discurso" (Foucault, 1979: 139-140). Pero, siguiendo al autor, los discursos no están permanentemente sometidos al poder o levantados contra él, sino que pueden ser su instrumento y su efecto, pero también punto de resistencia para sostener una estrategia opuesta; por ello consideramos que los contenidos regulan, pero también liberan y permiten la emergencia de nuevos sujetos.

Históricamente, los contenidos de los libros han sido resultado de distintas contiendas en varios momentos desde el siglo XX; han sido disputas entre distintos actores que pretenden mantener o transformar el orden sexual "legítimo", entre quienes pretenden naturalizar el orden patriarcal judeocristiano y quienes buscan ampliar la perspectiva e incluir nuevos derechos y a nuevos sujetos. Por contiendas, me refiero a enfrentamientos entre distintos actores en asuntos en los que el Estado tiene responsabilidad de responder (Mc Adam, Tarrow y Tilly, 2005). Por orden sexual me refiero a los límites normativos y discursivos establecidos respecto a los deseos, las prácticas eróticas, las formas de vinculación sexo-afectiva, las decisiones sobre el propio cuerpo y la vida reproductiva, así como respecto a las identidades y orientaciones sexogenéricas; considero que entre la sociedad existe un miedo a la pérdida de dicho orden y que es utilizado por los actores que se oponen a los avances en materia de educación sexual laica (Díaz, 2017). La religión desempeña un papel central en la conservación de dicho orden, a la vez que el miedo a la pérdida de ciertos límites marcados por ese orden "legítimo" permite la vigencia de valores y creencias religiosas judeocristianas; por ello es necesario retomar conceptos de secularización, que es el cambio cultural que ha llevado a la pérdida de la centralidad social de la religión, (Guimbelli, s.f.) y la laicidad, que es el régimen de ciertos límites de autonomía de los gobiernos y sus políticas respecto a lo religioso (Blancarte, 2008). Para los contenidos sobre educación sexual, la laicidad implica que estén basados en la ciencia y los derechos humanos, que atiendan asuntos prioritarios del orden de lo real como la salud, la convivencia pacífica, la inclusión, la construcción de proyectos de vida con erotismo y sin riesgo de embarazo, que respeten el principio de libertad de conciencia y den elementos para que las personas tomen las mejores decisiones, y que no discriminen por motivos basados en creencias religiosas acerca de temas como las orientaciones sexuales, las identidades sexo-genéricas, el inicio de la vida sexual activa, entre otras. 


\section{Los contenidos sobre educación sexual en el siglo XX}

Aunque el Estado laico mexicano se fundó en 1857, pasó más de un siglo para que se implementaran las primeras políticas públicas nacionales de educación sexual; se trata de temas expulsados de lo social, que paulatinamente fueron incluidos a través de diversos acontecimientos discursivos y condiciones sociales que los hicieron posibles, tales como disputas entre actores por conservar o transformar el orden social legítimo, avances en la ciencia, necesidades en materia de regulación de la salud y la población, la construcción de un marco normativo que respaldara la laicidad educativa en relación con la sexualidad, y cambios culturales que son parte del proceso de secularización. Hay contenidos de educación sexual en los libros oficiales desde hace 45 años, y se han relaborado como reflejo de cambios en el equilibrio de las relaciones de poder entre el Estado y las organizaciones religiosas, que han definido la capacidad de influencia de los actores involucrados en las contiendas por modificar los contenidos.

La primera contienda importante en el siglo XX fue entre 1932 y 1934 en el Distrito Federal; esta iniciativa fue posible gracias a que profesionales de la salud estaban al tanto de nuevos saberes como las teorías psicoanalíticas sobre el desarrollo psicosexual y los avances de una joven sexología; pero la fuerte legitimidad de la que gozaba la religión católica como principio ético, no permitió que se concretan políticas nacionales. La iglesia católica y la Unión Nacional de Padres de Familia lograron convencer a la comunidad con su discurso y generar apoyo a su movilización, lograron poner escuelas en huelga, e incluso tuvieron el apoyo de las asociaciones de padres de familia de los centros escolares; el tema era vivido como una afrenta para la población porque era visto como una amenaza, había padres de familia que afirmaban que preferían ver a su hijos muertos que con la inocencia perdida a causa de la educación sexual; esto significa que un amplio sector de la sociedad en esa época no estaba dispuesto a que sus hijas e hijos tuvieran una subjetividad sexual distinta a la propuesta por la religión; además, esta propuesta de política educativa era parte de una iniciativa de educación socialista, por lo que detonaba una reacción más violenta y no se pudo concretar, concluyó con la renuncia del secretario de Educación (Del Castillo, 2000).

Después vendría la época del modus vivendi (Blanacarte, 1993), un pacto político que buscaba mantener en paz la relación entre el Estado y la iglesia católica; el gobierno dejó la educación bajo la dirección de las organizaciones religiosas a pesar de que era el único ámbito reconocido por la Constitución como obligatoriamente laico; se trataba de un acuerdo en el que el gobierno cedía en educación a cambio de que la Iglesia se mantuviera al margen en otros ámbitos de la vida política y económica.

Este pacto tuvo una ruptura importante en 1959, pues la creación de la Comisión Nacional del Libro de Texto Gratuito detonó una contienda que fue clave para hacer posible la educación laica. Hubo importantes manifestaciones organizadas por la iglesia católica, la Unión Nacional de Padres de Familia, el Partido Acción Nacional (PAN) y editorialistas, pero no tuvieron la capa-

Diólo@os sobre Educación año 11 | número 21 | julio-diciembre 2020| ISSN 2007-2171 
cidad de detener esta iniciativa (Greaves, 2010). La aparición de los libros de texto obligatorios para primaria puso candados para asegurar que la perspectiva católica no fuera impuesta a la población como la única visión válida. Desde entonces, los libros de texto obligatorios albergan los contenidos mínimos que se pretende todas las personas conozcan, de esta manera se redefinió el concepto de educación pública y el Estado asumió la autoridad para definir los significados con los que se formará a los sujetos; marcó la pauta para que los gobiernos definieran valores cívicos sobre los cuales educar y formar a los sujetos, con ello se respeta la religión de cada quien y, a la vez, se busca proteger lo que se considera bien común y asegurar el respeto a la vida privada.

En 1974 se incluyó un apartado sobre la reproducción y desarrollo sexual en la adolescencia en los libros de sexto grado de ciencias naturales de primaria; la información permaneció hasta 1997, y se introdugeron algunos cambios en imágenes y mensajes en 1986 y 1988. Era parte de una política de población; el gobierno dejó de tener una perspectiva pronatalista y pasó a una de regulación de la natalidad. Desde esta nueva visión, la disminución del crecimiento poblacional era una prioridad con implicaciones económicas y políticas, de manera que la información no se detuvo, aunque hubo restricciones para evitar tocar temas eróticos y mostrar el cuerpo en desnudez. La Iglesia y organizaciones con perspectiva católica organizaron manifestaciones y quema de libros (Blancarte, 1993), logrando cambiar algunas imágenes, pero no detener la política. La inclusión fue posible también porque en esa época ya había organizaciones especializadas en educación sexual y un movimiento feminista que toma como prioridad el que las mujeres regulen su fecundidad y puedan construir proyectos de vida. Además, el Movimiento Familiar Cristiano se posicionó a favor de la política de población. Este acontecimiento discursivo da cuenta de cómo la influencia religiosa es evitada más fácilmente cuando hay actores seculares que defiendan la laicidad. En cuanto a la formación de sujetos, por primera vez se visualiza que se eduque sobre temas sexuales en todo el país, principalmente desde su dimensión biológica; estos libros muestran también discursos normativos sobre género; tienen una carácter performativo, pues sus imágenes y textos muestran modelos de lo que se supone es una mujer y un hombre (Butler, 2010), imponen un binarismo sexo-genérico que construye y naturaliza una materialidad del cuerpo sexuado como la base de una sexualidad ligada a la reproducción, y por lo tanto, impone la heterosexualidad como modelo único.

En 1993 se incluyó información sobre salud sexual en los libros de secundaria, por primera vez se hablaba de $\mathrm{VIH}$; se trataba de un tema que no era reductible porque había una infección que se trasmite sexualmente y que era mortal; para entonces se había visto que la educación sexual y el uso de condones eran la mejor opción para la prevención entre personas con vida sexual. En 1998 y 1999 se publicaron nuevos libros para quinto y sexto grado de primaria; en ellos se puede ver que se le da importancia a prevenir el VIH y el embarazo, pero es claro que la intención es que la información no se quede en lo biológico, por primera vez 
aparecen dibujos más claros que muestran el desarrollo del cuerpo de niñas y niños en desnudez, se evitan esquemas con los órganos sexuales aislados del resto del cuerpo, y es el único en el que se muestran los órganos sexuales externos de las mujeres. Estos libros fueron posibles gracias a que ya había un importante desarrollo de políticas en materia de sexualidad, actores de sociedad civil organizados en torno a los derechos sexuales y compromisos políticos con la comunidad internacional, pues México ya había firmado la Convención de Derechos del Niño y los acuerdos de El Cairo y Beiging, que fueron clave para evitar la influencia religiosa; además de que hubo pocas reacciones de organizaciones en contra de la educación sexual. Estos fueron los contenidos de educación sexual más laicos que ha tenido el país, hechos en una época en que se desquebraja la idea de una moral única y se avanza en derechos humanos de las mujeres. También reflejan el fin de una era, en la que se vislumbra que el Partido Revolucionario Institucional (PRI) deja de ser quien gobierna el país y en estos libros dejan ciertos avances, su sello antes de que los "conservadores" del PAN tomaran el mando. ${ }^{1}$ Finalmente, estos contenidos muestran un mayor interés para formar sujetos de sexualidad más allá de la biopolítica y se ve a los adolescentes como sujetos reconocidos como prioridad.

\section{Los contenidos en el nuevo milenio}

Este nuevo milenio trajo consigo la alternancia en el gobierno, el Poder Ejecutivo ha estado a cargo de tres partidos distintos, y cada uno ha tenido una relación distinta con la laicidad y con la educación de la sexualidad; además, el escenario de disputa ha cambiado debido a la participación y politización de nuevos actores religiosos. La construcción de la laicidad de la educación sexual no es lineal, el cambio de Gobierno Federal del año 2000 colocó en las instituciones y funcionariado proveniente del PAN, que no estaba a favor de la laicidad y que eran aliados ideológicos de los actores católicos. Hubo una nueva contienda en 2006, ahora por los contenidos de Ciencias 1 (biología) de primero de secundaria (Díaz, 2017). Entre los libros aprobados por la CONALITEG a distintas editoriales, se incluyó información sobre salud sexual y reproductiva, de la cual hubo algunos contenidos que detonaron polémica, tales como hablar del inicio de las relaciones sexuales, la masturbación como una actividad saludable y el anticonceptivo de emergencia, y algunos autores abordaron la homosexualidad. Durante varios meses hubo una intensa discusión mediática entre organizaciones con perspectiva católica y las de derechos sexuales, en las que las organizaciones conservadoras utilizaron dos repertorios discursivos: el primero, emitir mensajes que fomentaran el miedo a la pérdida del orden sexual, de hecho, la jerarquía católica calificó algunas prácticas y preferencias sexuales como "conductas desordenadas"; el segundo fue usar una argumentación que presentaba sus demandas religiosas en

1 El entrecomillado tiene como intención cuestionar la idea binarista de que un partido esté en contra de los derechos sexuales y otro a favor; en realidad, en ambos podemos encontrar diversidad de posiciones, aunque sea más frecuente la cercanía de los grupos conservadores con el PAN.

Diálo pos 
mensajes que parecían basados en la ciencia y los derechos humanos. Sus repertorios no lograron tener suficiente peso, así que implementaron una estrategia de alianzas y negociaciones, en las que consiguieron que la Secretaría de Educación Pública (SEP) entregara a las editoriales unos dictámenes en los que les exigía modificar contenidos en favor de la perspectiva católica. Las organizaciones de derechos sexuales lograron detener la mayoría de esas modificaciones mediante una denuncia pública y apoyo del funcionariado de la Secretaría de Salud, pero dejaron fuera el tema de la homosexualidad porque no estaba en el programa oficial y prefirieron dejarlo así al considerar que, si se modificaba el programa, podría haber más retrocesos que avances (Díaz, 2017). Estos nuevos contenidos, muestran la idea de un sujeto adolescente como sujeto a regular, pero también con derechos y libertades, de hecho, los libros de secundaria incluyen una cartilla de derechos sexuales hecha por la sociedad civil. Como los actores y funcionarios conservadores no lograron modificar los libros de secundaria como hubieran querido, en 2010 la SEP publicó nuevos textos de ciencias naturales para quinto y sexto de primaria; para elaborar este nuevo material decidieron hacer uso de la autoridad gubernamental y dejar el debate fuera de los medios de comunicación; así fue que produjeron contenidos menos laicos, que reflejan un regreso al viejo proyecto de formar sujetos más asexuales y menos identificados con los derechos humanos. Los contenidos incorporados desde 2006 hasta 2010 muestran que la democracia electoral no garantiza la laicidad, sino que resulta del cambiante equilibrio de poder entre los actores que se disputan la capacidad de influir en los contenidos. El uso de discursos seculares por parte de organizaciones con inspiración religiosa fue una estrategia con cierta eficacia que les permitió mantener un debate y lograr algunas modificaciones, pero su agenda no avanzó como esperaban, porque existe un amplio marco normativo que respalda la laicidad. Sin embargo, la alianza con gobierno les permitió influir en la política educativa cuando tomaron acuerdos con el gobierno que no se hicieron visibles a la opinión pública.

Durante el sexenio 2012-2018, el PRI volvió a estar a cargo del Gobierno Federal. El periodo fue más complejo porque ya las organizaciones con perspectiva católica no tuvieron la misma cercanía en espacios de toma de decisión en cuanto a leyes y políticas públicas. Sin embargo, desde 2016 tuvieron una fuerte presencia en medios de comunicación y redes sociales, además de hacer estrategias de incidencia política. Uno de los temas más importantes al inicio del sexenio fue que la Ley General de Protección de Niñas, Niños y Adolescentes establece que la educación sobre sexualidad debe impartirse por las instituciones educativas y debe regirse bajo los principios de interés superior de la niñez y de autonomía progresiva; también respalda que las instituciones de salud proporcionen orientación y métodos anticonceptivos a adolescentes. Los grupos conservadores acudieron a la Suprema Corte de Justicia de la Nación (SCJN), y solicitaron que se impugnaran varios artículos de esta ley, bajo el argumento de que "violan el interés superior del menor, discriminan a los niños en razón de su género, limitan indebidamente 
la patria potestad de los padres y crean un ambiente nocivo para niñas, niños y adolescentes" (SCJN, 2016).

Como se puede observar, la estrategia de estas organizaciones fue usar los mecanismos de la democracia participativa y los argumentos de derechos humanos para legitimar sus demandas, las cuales están basadas en criterios más religiosos que jurídicos; de hecho, la SCJN fue una instancia a la que gobiernos conservadores apelaron durante el sexenio anterior y que fue resolutiva a favor de los derechos sexuales en temas como sociedad de convivencia, aborto y matrimonio igualitario; por lo que dichas organizaciones la identificaron como una audiencia clave para dirigir sus demandas. Algo de lo que aprendieron durante la contienda de 2006 a 2007 fue que el repertorio discursivo de "el derecho de los padres" no fue efectivo, porque existe el principio de interés superior de la niñez; de esta manera, lo que hicieron fue matizar sus discurso mediante la noción de "patria potestad" y de argumentar como si su petición fuera por los derechos de la niñez.

El resultado de esta disputa no fue favorable para las organizaciones conservadoras; la SCJN resolvió que la ley no incurría en inconstitucionalidad y que es legítimo impartir educación sexual, reconocer la diversidad sexual y proporcionar anticonceptivos a adolescentes. La Corte emitió el comunicado 188/2016, donde afirma que las autoridades deben garantizar a las y los menores de edad el acceso a métodos anticonceptivos, así como proporcionar asesoría y orientación sobre salud sexual y reproductiva. En el comunicado, la Corte sostiene que la protección de niñas, niños y adolescentes es una responsabilidad tanto del Estado como de los padres y madres, y que se les debe instruir, orientar y proporcionar información para fomentar un desarrollo pleno y evitar prácticas que puedan poner en peligro su integridad física, mental y psicológica. La Corte sostiene que el ejercicio de la patria potestad tiene un límite jurídico, que implica evitar acciones de los padres que puedan atentar contra la dignidad y seguridad de las niñas, niños y adolescentes.

Un segundo tema de discusión fue que en 2016 se publicaron nuevos libros oficiales de ciencias de sexto grado de primaria, que incluyeron información específica sobre cada uno de los métodos anticonceptivos. Este cambio resulta de viarios factores; el primero fue que la información se volvió necesaria ante la preocupación por el incremento de embarazos en adolescentes; la Encuesta Nacional de la Dinámica Demográfica (ENADID) ${ }^{2}$ reportó que la tasa de fecundidad entre mujeres de 15 a 19 años había bajado de $81.4 \%$ en 1990 a 64.4\% en 2004, pero luego se incrementó hasta llegar a 77\% en 2014. Esta situación ha representado un desafío para las instituciones, porque la población adolescente cada vez está más excluida de la posibilidad de un trabajo formal que ofrezca prestaciones en materia de servicios de salud, seguridad social y fondos para vivienda. En este contexto, el embarazo puede incrementar el riesgo y precarie-

2 CONAPO (2016). Situación de la salud sexual y reproductiva, República Mexicana.

Diólo pos sobre Educación año 11 | número 21 | julio-diciembre 2020| ISSN 2007-2171 
dad económica en la vida de las y los adolescentes; además de que los casos de menores de 15 años que se embarazan refleja un problema fuerte de abuso sexual infantil. De hecho, la inclusión de información sobre metodología anticonceptiva es parte de la Estrategia Nacional para Prevención de Embarazo en Adolescentes (ENAPEA), un trabajo articulado entre distintas instituciones para resolver esta situación. La ENAPEA es una medida biopolítica, porque se corre el riesgo de que las instituciones se vean rebasadas por el incremento de nacimientos en situación de exclusión social, pero también es una respuesta que busca mejorar las condiciones de vida de las y los adolescentes, y que considera un componente con líneas de acción específicas en materia de educación sexual, además de materiales informativos de utilidad. ${ }^{3}$ Un segundo factor que permitió la inclusión de contenidos sobre anticonceptivos fue que existe un amplio marco normativo que los respalda, que incluye las leyes y normas sobre salud, educación, juventud y discriminación (véase Díaz, 2018). Por último, no hay que descartar que el Departamento de Materiales y Métodos de la SEP estaba de nuevo a cargo de funcionariado con perfil liberal; era dirigido por Elisa Bonilla, quien fue responsable de avances muy importantes en los contenidos oficiales, como los libros de quinto y sexto grado de 1998 y del programa oficial de 2006, que en materia de educación sexual sólo ha tenido algunas modificaciones y mucha información continúa vigente.

En 2016, las organizaciones con perspectiva católica se aliaron con grupos evangélicos y formaron el Frente Nacional por la Familia, un conjunto de organizaciones de todo el país que se articula con agrupaciones y redes análogas en el continente y el mundo. Este actor se movilizó en contra de la iniciativa presidencial que pretendía llevar a rango constitucional el derecho a la identidad y al matrimonio igualitario con posibilidad de adopción. Durante ese año, organizaron marchas multitudinarias en varias ciudades del país, ${ }^{4}$ hicieron fuerte presencia en medios de comunicación y, en años siguientes, desarrollaron una campaña llamada "No te Metas con mis Hijos" y realizaron una gira por varias ciudades a las que llevaron "el bus de la libertad", su estrategia consiste en acusar al Estado de violar los "derechos de los padres" a educar a sus hijos y promover el temor hacia la posibilidad de que se liberen las personas y experimenten la diversidad sexual y de género. En este episodio, dichas organizaciones mostraron una mayor profesionalización en el manejo de su discurso; crearon mensajes estratégicos para atraer el apoyo de actores no movilizados que se identificaran con sus demandas; sus mensajes se enfocaron a fomentar el miedo a la pérdida del orden sexual y a desacreditar los discursos de género y derecho sexuales. Su recurso más poderoso fue el concepto "ideología de género", que contraviene la idea de que el género se deriva del sexo biológico y el deseo tiene una base reproductiva, de esta manera acusan a los movimientos feministas y de diversidad sexual de difundir ideas falsas y de promover comportamientos que ponen en riesgo a la sociedad. Se trata de una

3 https://www.gob.mx/cms/uploads/attachment/file/55979/ENAPEA 0215.pdf

4 https://www.jornada.com.mx/2016/09/11/politica/002n1pol 
versión más elaborada del uso de argumentos que se asemejan a los discursos seculares de la ciencia y los derechos humanos. Este recurso político ha sido utilizado en todo el mundo y está mostrando eficacia política, los ejemplos más claros son que lograron detener el acuerdo de paz en Colombia y han provocado importantes retrocesos en las políticas relacionadas con los derechos sexuales en Brasil.

Un tercer tema de discusión fue la inclusión de conceptos sobre diversidad sexual en los libros de Ciencias 1 (biología) de secundaria, único cambio relevante en esos textos desde 2007. De 17 libros aprobados, nueve ofrecen las definiciones de las orientaciones e identidades que salen del modelo de heterosexualidad obligatoria y binarismo sexo-genérico; el texto de Luz Lazos y el de Mora Villa incluyen un poco más de información; afirman que ninguna preferencia sexual es incorrecta, presentan las identidades y expresiones de género disidentes como formas de expresión de la individualidad y no como problema, además, incluyen mensajes en contra de la violencia y la discriminación por diversidad sexual y de género. La inclusión de este contenido fue posible debido a la configuración de relaciones de fuerza; los grupos conservadores lograron tener influencia para detener la iniciativa presidencial, pero no pudieron evitar la inclusión de esta información en los libros oficiales porque los contenidos son atribución del Poder Ejecutivo, de manera que la Dirección de Materiales y Métodos de la SEP siguió las instrucciones presidenciales. La publicación de los nuevos libros fue motivo de reacciones de las organizaciones con perspectiva católica y cristiana, como se observa en declaraciones de sus voceros, quienes trataron de argumentar que era un error la inclusión del tema: "Hay que enseñarle al niño que ésa puede ser una orientación cuando crezca, pero si ahorita no [ha] madurado, basta con que le enseñemos a respetar (Leonardo García Camarena, UNPF, Millenio, 28/06/2018). ${ }^{5}$

En esta etapa, la información sobre diversidad sexual es muy importante para que las personas que salen del modelo de heterosexualidad obligatoria y binarismo sexo-genérico aprendan a aceptarse a sí mismas y para prevenir el acoso escolar por estos motivos. De hecho, la Encuesta Nacional sobre Discriminación por Orientación Sexual o Identidad de Género (ENDOSIG, 2016) reporta que $45.7 \%$ de lesbianas, gays y bisexuales siempre supieron su orientación sexual o la descubrieron durante su infancia; mientras que entre personas trans, intersexuales y no binarias, esta cifra es de $49.1 \%$. Además, $26.8 \%$ de quienes se dieron cuenta de su condición antes de la mayoría de edad reportaron haber vivido alguna forma de agresión física en la escuela.

La inclusión de estos conceptos abre la oportunidad de ampliar los márgenes del orden sexual "oficial" al reconocer positivamente la existencia de sujetos que el discurso educativo había mantenido excluidos. Si bien cualquier adolescente puede acceder a información sobre diversidad sexual a través de redes digitales, la inclusión en los contenidos oficiales representa un reconocimiento y legitimación de la diversidad sexual y de género. Después de más de una

5 http://www.milenio.com/cultura/nuevos-libros-de-la-sep-en-sintonia-con-la-constitucion

6 https://www.conapred.org.mx/userfiles/files/Resumen_Ejecutivo_ENDOSIG_16-05_2019\%281\%29.pdf

DióloPos 
década de que se aborda la violencia de género y el acoso escolar, por fin se materializa un mensaje para la prevención de la discriminación por orientación sexual e identidad de género; este es un avance en la construcción de la laicidad educativa, pues toma discursos seculares como la ciencia y los derechos humanos como referentes válidos y criterios de verdad en la formación de los sujetos.

Para finales de 2019 e inicio de 2020, tenemos un panorama ambivalente; por un lado, el nuevo gobierno ha tenido acciones que claramente violan el principio de laicidad, pues se ha hecho pública la cercanía de organizaciones evangélicas con el presidente López Obrador ${ }^{7}$ y la intención de facilitarles acceso a medios de comunicación; además, declaró su interés de incluirlos como promotores de la "Cartilla Moral", que es parte de una estrategia muy cuestionable para abordar el problema de la violencia y la delincuencia organizada en el país, por varias razones: la primera es que no se requiere una cartilla moral sino que tendrían que difundirse los valores cívicos de la Constitución; la segunda es que dicha iniciativa no garantiza algún efecto, porque parte de la falsa idea de que las religiones son el "mejor camino" para promover una cultura de paz y van a resolver un proceso de deshumanización que ha adquirido importantes dimensiones en varios estados del país, pero además, porque fortalece la cercanía política de actores religiosos al darles juego en acciones de política pública que competen al Estado. La presencia de lo religioso en el discurso presidencial está latente desde el hecho de que el partido Movimiento de Reconstrucción Nacional (MORENA) fue fundado un 12 de diciembre y representa una clara alusión a una figura religiosa: "la Virgen Morena"; y se ha hecho evidente en varios momentos, el más reciente es que a finales de octubre pasado comparó las políticas y programas sociales de su gobierno con el cristianismo.

El propósito, repito, es que tengan mejores condiciones de vida y de trabajo para los más necesitados, esto es humanismo, es justicia social, y es también cristianismo. Me van a criticar, pero miren ¿por qué sacrificaron a Jesucristo?... por defender a los más humildes (Andrés Manuel López Obrador, El Universal, 26/10/2019). ${ }^{9}$

Por otro lado, hemos sido testigos de dos avances importantes: el primero es que se incluye el concepto orientación sexual en los contenidos sobre el derecho a la no discriminación en los libros de Formación Cívica y Ética de quinto de primaria; era un tema pendiente desde 2001, año en que se incluyó el término en el artículo primero constitucional; esta inclusión ha sido ne-

7https://www.excelsior.com.mx/nacional/evangelicos-impulsan-agenda-en-los-tres-poderes-desde-febrero-ha-habido-un-boom-deradios?fbclid=IwAR1w9dM_xHggbOgN9JYWUym0ogbgD-rp2pFmTOdSyB6u1vUN5yJgkxajl9M

8 https://www.eluniversal.com.mx/nacion/evangelicos-alistan-distribucion-de-la-cartilla-moral?fbclid=IwAR1QyOEVzFMTJgyVLnnTyQOoAHc TFpFAe-Gpl3ckQMhjDXD9zsaUcWOPGAE

9 https://www.eluniversal.com.mx/nacion/politica/amlo-compara-su-gobierno-con-el-cristianismo 
cesaria porque cerca de la mitad de las personas LGBTTTI+ se da cuenta de su orientación sexual o identidad de género antes de la adolescencia. Aunque no se incluya más información sobre el tema, la enunciación de personas que salen del modelo de heterosexualidad obligatoria y binarismo sexo-genérico es un paso hacia el reconocimiento de estos sujetos de derecho, cuya existencia había sido negada en la educación pública, con el fin de evitar que las y los niños se identificaran con la diversidad sexual.

Un segundo avance para la laicidad en educación sexual llegó con la reforma del artículo tercero constitucional, publicada el 15 de mayo de $2019 .{ }^{10}$ El artículo sigue decretando la laicidad como un principio de la educación que imparte el Estado, como lo ha establecido desde 1917, pero es más explícito respecto a que su área de autoridad es más amplia, pues especifica que "corresponde al Estado la rectoría de la educación".11 De esta manera, queda entendido que le corresponde establecer ciertas regulaciones porque sus contenidos y la perspectiva desde la que se imparte repercuten en la sociedad, es decir, son un asunto público. El artículo tercero ofrece la mejor definición de la laicidad educativa, pues plantea que debe regirse por una serie de principios seculares tales como "basarse en los derechos humanos, tenderá a desarrollar armónicamente todas las facultades del ser humano y fomentará en él [...] el respeto a todos los derechos, las libertades, la cultura de paz", "se mantendrá por completo ajena a cualquier doctrina religiosa"(Fracción I), y"se basará en los resultados del progreso científico, luchará contra la ignorancia y sus efectos, las servidumbres, los fanatismos y los prejuicios" (Fracción II).

Uno de los aportes de la reforma es que se establece que la educación básica impartida en instituciones educativas "particulares" debe apegarse a los principios que marca el artículo tercero; en esta nueva redacción, las escuelas dirigidas por la iniciativa privada no son denominadas como "privadas", lo cual tiene implícita una redefinición de la noción de educación pública como aquella a la que distintas personas pueden acceder y cuyas enseñanzas tienen efectos en la formación de los sujetos y su vida en sociedad; es decir, repercute en la formación de ciudadanas y ciudadanos cuyo bienestar y convivencia pacífica deben ser garantizados por el Estado. De esta manera, puede tenerse una mayor posibilidad de asegurar que quienes imparten educación con implicaciones públicas se ajusten a los contenidos mínimos que se establecen en los programas oficiales; y tomar medidas para que la iniciativa privada no eduque desde posturas antigénero ni evada el principio de laicidad o la educación sexual, a la vez que tenga la libertad de incluir contenidos y prácticas religiosas que estén dentro de la ley.

Los particulares podrán impartir educación en todos sus tipos y modalidades [...] En el caso de la educación inicial, primaria, secundaria y normal, los particulares deberán [...] impartir la educación con apego a los mismos fines y criterios que establece el párrafo cuatro y la Fracción ll, así como cumplir los planes y programas (Fracción VI).

10 http://www.dof.gob.mx/nota_detalle.php?codigo=5560457\&fecha=15/05/2019

11 https://www.juridicas.unam.mx/legislacion/ordenamiento/constitucion-politica-de-los-estados-unidos-mexicanos-10538

Diólopos 
Esta reforma hace también un aporte en los temas que nos interesan, pues establece que "los planes y programas de estudio tendrán perspectiva de género y una orientación integral, por lo que se incluirá el conocimiento de [...] la educación sexual y reproductiva". Este nuevo texto representa una herramienta para la defensa de la laicidad y reconoce mayor legitimidad a una serie de temas que han permanecido excluidos, con distintos grados, del campo de lo social, pues actualmente continúa habiendo posicionamientos de grupos conservadores que tratan de desacreditar la educación sexual y pretenden que el Estado no se haga cargo de garantizarla; aún persisten padres de familia que no están de acuerdo en que los temas se revisen en las escuelas, y persisten los casos de maestros que evaden los temas por ignorancia o prejuicio. Al enunciarse al educación sexual integral como principio constitucional, el carácter obligatorio de los contenidos oficiales está mejor respaldado, lo cual resulta necesario en el contexto actual de fuertes tensiones en las escuelas y en los espacios públicos.

Pero una reforma jurídica no garantiza una laicidad en la práctica. Es necesario que se realicen acciones de formación docente y orientación a padres y madres de familia si se quiere contrarrestar los efectos de la falta histórica de educación sexual y de los discursos conservadores, cuya difusión se ha incrementado desde 2016. Si bien desde 2006 estos actores ya hacían uso de argumentos en clave de ciencia y derechos humanos, sus repertorios discursivos se volvieron más eficaces en 2016, cuando se discutía la iniciativa presidencial en materia de derecho a la identidad de género y matrimonio con posibilidad de adopción por parejas del mismo sexo. Al parecer, el reconocimiento a ciertos derechos en el contexto de la diversidad sexual resultó amenazante para bastante gente y lograron capitalizarlo; ahora el país tiene la paradoja de un discurso jurídico más fuerte respecto a la protección de la laicidad educativa y la educación sexual, mientras que la oposición al avance en estos aspecto ha crecido en visibilidad, además de que muestra una importante presencia entre la población; de hecho, la Encuesta Nacional sobre Creencias y Prácticas Religiosas en México (ENCREER, 2016) ${ }^{12}$ reporta que $18.4 \%$ de la población encuestada no está de acuerdo con la enseñanza sobre sexualidad en las escuelas públicas y $25.8 \%$ está en contra de los contenidos en los libros de texto escolares. Esta situación contradictoria nos permite visualizar que habrá futuros enfrentamientos discursivos sin que se resuelva la tensión respecto al papel del Estado y al tipo de sujetos sexuales que se pretende producir a través de la educación pública.

\section{Reflexiones finales}

El siglo XX se caracterizó por una construcción de la laicidad que no transformó la educación durante varias décadas, a pesar de que ya era un principio constitucional. Hasta antes de 1974 no hubo una política nacional de educación sexual, debido a la fuerza de la exclusión que lo-

12 http://www.rifrem.mx/wp-content/uploads/2017/10/INFORME-DE-RESULTADOS-EncuestaNacionalMexicoCreenciasyPracticasReligiosas-2017-05. pdf 
graba generar la religión, con un intento fallido durante la contienda de los años treinta y una posterior falta de posibilidades de que emergiera debido a que la educación era objeto de un pacto político que dejaba la educación en las manos de organizaciones religiosas. El primer andamiaje para posibilitar una política de educación sexual fue puesto en 1960, cuando se logró que los programas educativos se materializaran en libros oficiales y obligatorios.

A lo largo de los últimos 45 años ha habido contenidos oficiales sobre educación sexual; en ellos se observa que las organizaciones con perspectiva católica (ahora también cristiana) han tenido una cambiante capacidad de influencia. Los contenidos de 1974 y 1998 dan cuenta de una construcción de la laicidad educativa marcada por avances, con tendencia a una mayor autonomía de lo político respecto a lo religioso, esto gracias al proceso de secularización. Los contenidos sobre educación sexual en primaria y secundaria fueron posibles por el reconocimiento de la ciencia como criterio de verdad, por la priorización de problemáticas demográficas y de salud que colocaron el campo de lo real por encima de creencias y morales religiosas; pero también por una creciente legitimidad social de los valores democráticos como referentes éticos.

Se observa un cambio en las relaciones de poder y en el uso de estrategias y alianzas en cada época. Las organizaciones con perspectiva católica fueron perdiendo su influencia sobre los contenidos hacia finales del siglo $\mathrm{XX}$, pero al iniciar el nuevo milenio cobraron fuerza mediante sus alianzas con los gobiernos panistas; la contienda de 2006 dio como resultado que los discursos católicos no lograron colocarse plenamente en los contenidos de los libros de secundaria gracias a que no tuvieron un sustento que fuera reconocido como legítimo por la opinión pública y debido a que la educación sexual se encuentra respaldada en un nutrido marco normativo nacional e internacional, pero el gobierno hizo modificaciones conservadoras a los libros de ciencias naturales de 2010 evitando la discusión pública, los conservadores estaban insertos en el gobierno e hicieron uso del poder de manera vertical para lograr sus objetivos sin tener enfrentamientos con sus adversarios.

En el nuevo milenio, la construcción de la laicidad de la educación sexual dejó de ser progresiva, como lo fue en las últimas décadas del siglo XX. Si bien los discursos seculares como la ciencia y los derechos humanos han ido desplazando la influencia de la moral judeocristiana, sigue habiendo importantes tensiones que dificultan abordar la información en temas como la desnudez, la educación a niños, la homosexualidad, el derecho al placer, la masturbación, el aborto, y el uso de condones y anticonceptivos. Vimos llegar al gobierno a sujetos con una formación más religiosa, donde su fe atraviesa la idea de país que quieren construir y el sentido que dan a la función pública; después, vimos emerger un movimiento neoconservador que, aún sin un vínculo fuerte con el gobierno, logró sumar actores y tener influencia. Aquí es donde se observa una contradicción: la eficacia política de la religión se va perdiendo con la secularización, pero eso no excluye la posibilidad de que sujetos con creencias religiosas firmes ejerzan el poder, desde dentro o fuera del gobierno, e influyan en las políticas de derechos sexuales. 
En la administración 2012-2018, las organizaciones con perspectiva católica no gozaron de la misma cercanía con el gobierno, pero resurgieron en su alianza con los grupos evangélicos, un actor con una presencia cada vez mayor en la esfera pública; de esta manera, construyeron nuevas estrategias que hacen resurgir el conservadurismo, como lo han logrado en varios países del continente y del mundo. El regreso del PRI al Gobierno trajo un nuevo avance: se incluyeron los anticonceptivos y se lograron contenidos más laicos para 2016; pero los grupos con perspectiva católica y cristiana se colocaron a la delantera en los debates sobre educación sexual, derechos sexuales, identidad de género y matrimonio igualitario, de manera que lograron movilizar actores en su apoyo y detener la iniciativa presidencial sobre esos temas, mostrando una nueva capacidad de influencia conservadora en las políticas públicas.

Actualmente, se incluye información básica sobre sexualidad en primaria y secundaria, que contiene los conceptos sobre diversidad en algunos libros, pero la alianza entre actores con perspectiva católica y evangélica continúa teniendo fuerza y representa riesgos de retrocesos en el reconocimiento de los derechos sexuales y reproductivos. A pesar de no tener una alianza directa con quienes toman las decisiones acerca de las políticas y materiales educativos, la fuerza de los argumentos antigénero incrementó el poder para cuestiones legislativas, pero no logró detener las decisiones del Poder Ejecutivo. Sin embargo, es necesario seguir documentando las estrategias y discursos de grupos conservadores, porque su avance en otros países ha sido fuerte $y$, aunque en México existe un importante soporte jurídico y una cultura de legitimidad de la laicidad, no podemos menospreciar los riesgos.

La situación es contradictoria en la nueva administración (2018-2024), pues se ha hecho visible una alianza con grupos evangélicos que viola el principio de laicidad, a la vez que se reformó la ley para hacer más laica la educación en sexualidad y género. El desafío será evitar la influencia religiosa en el currículum formal, que implica lograr la congruencia en los planes, programas y materiales; pero sobre todo, de aterrizar en acciones concretas que hagan una realidad la educación sexual en las aulas, lo que requiere de formación docente, intervención con madres y padres para atender sus preocupaciones y que dejen de estar en oposición, y también el de articular políticas como prevención de embarazos, infecciones y violencias. De otra manera no podrán implementarse realmente los contenidos, mucho menos de temas sensibles como la diversidad sexual.

\section{Referencias bibliográficas}

Blancarte, R. (1988). Historia de la Iglesia católica en México. México: FCE/El Colegio Mexiquense. Blancarte, R. (2008). Introducción / El porqué de un Estado laico. Los retos de la laicidad y la secularización en el mundo contemporáneo. México: El Colegio de México, 9-47.

Blancarte, R. (2012).¿Cómo podemos medir la laicidad? Estudios Sociológicos, 30(88), 233-247. 
Bourdieu, P.; J.C. Passeron (2005). La reproducción, elementos para una teoría del sistema de enseñanza. México: Fontamara.

Butler, J. (2004). Lenguaje, poder e identidad. España: Síntesis.

Butler, J. (2010). Cuerpos que importan. Sobre los límites materiales y discursivos del "sexo". Buenos Aires: Paidós.

Butler, J. (2014). Mecanismos psíquicos del poder. Universidad de Valencia/Ediciones Cátedra.

Del Castillo Troncoso, A. (2000). La polémica en torno a la educación sexual en la ciudad de México durante la década de los años treinta: Conceptos y representaciones de la infancia. Estudios Sociológicos, 18(52), 203-226.

Durkheim, E. (2013). Las formas elementales de la vida religiosa. México: Colofón.

Foucault, M. (1986). El uso de los placeres. Historia de la sexualidad 2. México: Siglo XXI.

Foucault, M. (1994). Diálogo sobre el poder. Obras Esenciales, 3, 59-72.

Foucault, M. (2007). La voluntad de saber. Historia de la sexualidad 1. México: Siglo XXI.

Giddens, A. (1998). La transformación de la intimidad. Sexualidad, amor y erotismo en las sociedades modernas. Madrid: Ediciones Cátedra.

Greaves, C. (2010). La búsqueda de la modernidad. En Tanck de Estrada, D. (coord.). Historia mínima: La educación en México. México: El Colegio de México.

Mc Adam, D.; S. Tarrow; Ch. Tilly (2005). La dinámica de la contienda. Barcelona: Editorial Hacer.

Suprema Corte de Justicia de la Nación (2016). Determina Segunda sala Constitucional Ley General de Niñas, Niños y Adolescentes. http://www.internet2.scjn.gob.mx/red2/comunicados/ noticia.asp?id $=4412$

Weeks, J. (1996). Sexualidad. Barcelona: Paidós. 